\title{
Erratum to: Scalable One-Step Electrochemical Synthesis of a Graphene-Based Material with Controlled Morphology
}

\author{
A. V. Kirianova ${ }^{a}$, X. Xieyu ${ }^{a}$, M. O. Gallyamov ${ }^{a, b}$, and O. O. Kapitanova ${ }^{a, c, *}$ \\ Presented by Academician A.R. Khokhlov April 5, 2021
}

Received November 8, 2021; revised November 8, 2021; accepted November 8, 2021

DOI: $10.1134 / \mathrm{S} 0012501621390020$

The article "Scalable One-Step Electrochemical Synthesis of a Graphene-Based Material with Controlled Morphology," written by A. V. Kirianova, X. Xieyu, M. O. Gallyamov, and O. O. Kapitanova, was originally published electronically in SpringerLink on 22 September 2021 without Open Access. After publication in volume 498, issue 2, pages 61-66 the authors decided to make the article an Open Access publication. Therefore, the copyright of the article has been changed to (C) The Author(s), 2021 and the article is forthwith distributed under the terms of a Creative Commons Attribution 4.0 International License (http://creativecommons.org/licenses/by/4.0/, CC BY), which permits use, duplication, adaptation, distribution and reproduction of a work in any medium or format, as long as you cite the original author(s) and publication source, provide a link to the Creative Commons license, and indicate if changes were made.

The original article can be found online at https://doi.org/10.1134/S0012501621060014

\footnotetext{
${ }^{a}$ Moscow State University, Moscow, 119991 Russia

${ }^{b}$ Nesmeyanov Institute of Organoelement Compounds, Russian Academy of Sciences, Moscow, 119991 Russia ${ }^{c}$ Moscow Institute of Physics and Technology, Dolgoprudny, Moscow oblast, 141701 Russia

*e-mail: olesya.kapitanova@gmail.com
} 